\title{
Dead space: the physiology of wasted ventilation
}

\author{
H. Thomas Robertson
}

\author{
Number 9 in the series "Physiology in respiratory medicine" \\ Edited by R. Naeije, D. Chemla, A. Vonk-Noordegraaf and A.T. Dinh-Xuan
}

\section{Affiliation:}

Division of Pulmonary and Critical Care Medicine, University of Washington, Seattle, WA, USA.

\section{Correspondence:}

H. Thomas Robertson, Division of Pulmonary and Critical Care Medicine, Depts of Medicine and Physiology and Biophysics, University of Washington, Box 356522 Seattle, WA, 98195-6522, USA.

E-mail: tomrobtauw.edu

ABSTRACT An elevated physiological dead space, calculated from measurements of arterial $\mathrm{CO}_{2}$ and mixed expired $\mathrm{CO}_{2}$, has proven to be a useful clinical marker of prognosis both for patients with acute respiratory distress syndrome and for patients with severe heart failure. Although a frequently cited explanation for an elevated dead space measurement has been the development of alveolar regions receiving no perfusion, evidence for this mechanism is lacking in both of these disease settings. For the range of physiological abnormalities associated with an increased physiological dead space measurement, increased alveolar ventilation/perfusion ratio $\left(V^{\prime} \mathrm{A} / Q^{\prime}\right)$ heterogeneity has been the most important pathophysiological mechanism. Depending on the disease condition, additional mechanisms that can contribute to an elevated physiological dead space measurement include shunt, a substantial increase in overall $V^{\prime} \mathrm{A} / Q^{\prime}$ ratio, diffusion impairment, and ventilation delivered to unperfused alveolar spaces.

$@$ ERSpublications

A review of current understanding of factors accounting for abnormal physiological dead space measurements in disease http://ow.ly/Dnyw1

\begin{abstract}
The online version of this article has been corrected. The correction is outlined in the erratum published in the October 2015 issue of the European Respiratory Journal [DOI: 10.1183/09031936.50137614].

Previous articles in this series: No. 1: Naeije R, Vachiery J-L, Yerly P, et al. The transpulmonary pressure gradient for the diagnosis of pulmonary vascular diseases. Eur Respir J 2013; 41: 217-223. No. 2: Hughes JMB, van der Lee I. The TL,NO/TL,CO ratio in pulmonary function test interpretation. Eur Respir J 2013; 41: 453-461. No. 3: Vonk-Noordegraaf A, Westerhof N. Describing right ventricular function. Eur Respir J 2013; 41: 1419-1423. No. 4: Hamzaoui O, Monnet X, Teboul J-L. Pulsus paradoxus. Eur Respir J 2013; 42: 1696-1705. No. 5: Prisk GK. Microgravity and the respiratory system. Eur Respir J 2014; 43: 1459-1471. No. 6: Dempsey JA, Smith CA. Pathophysiology of human ventilatory control. Eur Respir J 2014; 44: 495-512. No. 7: Petersson J, Glenny RW. Gas exchange and ventilation-perfusion relationships in the lung. Eur Respir J 2014; 44: 1023-1041. No. 8: Wagner PD. The physiological basis of pulmonary gas exchange: implications for clinical interpretation of arterial blood gases. Eur Respir J 2015; 45: 227-243.
\end{abstract}

Received: July 272014 | Accepted after revision: Sept 292014 | First published online: Nov 132014

Conflict of interest: None declared.

Copyright OERS 2015 


\section{Introduction}

Recent recognition of the prognostic relevance of measurements of physiological dead space for patients with the acute respiratory distress syndrome (ARDS) has brought new attention to a simple gas exchange calculation described over 120 years ago. The current calculation of physiological dead space, utilising measurements of arterial $\mathrm{CO}_{2}$ tension $\left(\mathrm{PaCO}_{2}\right)$ and mixed expired $\mathrm{CO}_{2}$ tension $\left(P \mathrm{ECO}_{2}\right)$, was initially thought to include an anatomical dead space, representing the fraction of ventilation advancing no further than the conducting airways, and an alveolar dead space, representing the fraction of ventilation delivered to alveolar surfaces receiving no pulmonary artery perfusion. With the subsequent development of a simple measurement of anatomical dead space, it became apparent that the alveolar dead space component was substantially increased in a range of pulmonary diseases, and that its original interpretation as ventilation delivered to unperfused alveolar surfaces was not adequate to explain the pathophysiology of most disease conditions. This review will cover the findings in gas exchange pathophysiology that shape our current understanding of the factors that influence physiological dead space measurements, with a primary focus on dead space measurements acquired in patients with respiratory or cardiac diseases.

\section{Bohr dead space}

Because of the tidal nature of ventilation, every exhaled breath contains a fraction of the inspired gas that does not participate in gas exchange. In 1891, the Danish respiratory physiologist Christian Bohr introduced his calculation to represent the volume of gas within the conducting airways that constituted the respiratory dead space [1]. The Bohr model conceptually divided the volume of the exhaled breath $(V \mathrm{~T})$ into two compartments, with the first $(V \mathrm{~A})$ representing the fraction of exhaled breath participating in gas exchange, and the second $(V D)$ representing the fraction of exhaled breath penetrating no further than the conducting airways, the respiratory dead space:

$$
V \mathrm{~T}=V \mathrm{~A}+V \mathrm{D}
$$

The Bohr calculation utilised two measurements of exhaled $\mathrm{CO}_{2}$ : the fractional $\mathrm{CO}_{2}$ concentration in the total mixed exhaled breath $\left(\mathrm{FECO}_{2}\right)$, and an estimate of mean alveolar $\mathrm{CO}_{2}$ concentration $\left(\mathrm{FACO}_{2}\right)$ based on a sample of gas collected late in exhalation. The mass balance calculation using $\mathrm{CO}_{2}$ assumes the dead space contributes no $\mathrm{CO}_{2}$ to the exhaled breath $\left(\mathrm{FDCO}_{2}=0\right)$ :

$$
V \mathrm{~T} \times \mathrm{FECO}_{2}=V \mathrm{~A} \times \mathrm{FACO}_{2}+V \mathrm{D} \times \mathrm{FDCO}_{2}
$$

Substituting $(V \mathrm{~T}-V \mathrm{D})$ for $V \mathrm{~A}$ yields:

$$
V \mathrm{~T} \times F \mathrm{ECO}_{2}=(V \mathrm{~T}-V \mathrm{D}) \times F \mathrm{ACO}_{2}
$$

Rearranging the terms describes $V \mathrm{D} / V \mathrm{~T}$, the fraction of ventilation not contributing to $\mathrm{CO}_{2}$ exchange:

$$
V \mathrm{D} / V \mathrm{~T}=\left(\mathrm{FACO}_{2}-F \mathrm{ECO}_{2}\right) / F \mathrm{ACO}_{2}
$$

The Bohr estimates of the volume of respiratory dead space correlated reasonably well with anatomical measurements of the respiratory pathway, and represented a noninvasive means of measuring the extent of ventilation inefficiency attributable to the constraints of tidal ventilation.

In the decades following the introduction of the Bohr dead space estimate, two factors that interfered with the accuracy of the measurement as an index of conducting airways volume became apparent. The development of a method to sample multiple within-breath samples of $\mathrm{CO}_{2}$ [2] demonstrated modest variability in partial pressures within an exhaled breath in normal subjects, leading to the recognition that a gas sample captured within a breath would not necessarily reflect the true mean alveolar gas composition. While that effect was minor in normal subjects, it became a substantial source of variability in patients with significant underlying lung disease. Furthermore, Bohr calculations performed on such patients revealed increases in dead space fraction that could not be ascribed to conducting airway volume. While the latter finding was an insight that drove subsequent investigations of gas exchange pathophysiology, problems with identifying a simple method to identify mean alveolar $\mathrm{CO}_{2}$ tension $\left(P \mathrm{ACO}_{2}\right)$ in patients with lung disease led to the later abandonment of the traditional Bohr measurement.

Current airway $\mathrm{CO}_{2}$ monitoring systems for intubated patients provide accurate measurements of end-tidal $\mathrm{CO}_{2}$ concentrations that are acceptable estimates of alveolar $\mathrm{CO}_{2}$ in normal subjects, and reflect at least directional changes in alveolar $\mathrm{CO}_{2}$ in patients with underlying lung disease, but cannot provide an accurate 
measurement of Bohr dead space in a diseased lung because the end-tidal $\mathrm{CO}_{2}$ does not reflect the mean alveolar $\mathrm{CO}_{2}$. One current application of the traditional Bohr measurement that substitutes end-tidal $\mathrm{CO}_{2}$ measurements for mean alveolar $\mathrm{CO}_{2}$ is seen with commercial exercise testing systems that calculate a Bohr dead space during exercise. At rest, $\mathrm{CO}_{2}$ concentrations measured within a single exhalation increase modestly, a consequence of a constant mixed venous $\mathrm{CO}_{2}$ delivery and the intermittent inspiration of fresh gas into the alveoli. However, during heavy exercise, when mixed venous $\mathrm{CO}_{2}$ tension $\left(\mathrm{PCO}_{2}\right)$ may exceed 60 $\mathrm{mmHg}$, exhaled $\mathrm{CO}_{2}$ concentrations increase substantially within the course of each exhaled breath. Hence during heavy exercise, although mean alveolar $\mathrm{CO}_{2}$ concentrations within an exhaled breath still approximate arterial values, the end-tidal values are substantially higher than the mean alveolar values. JONES et al. [3] documented end-tidal $P_{\mathrm{CO}_{2}}$ measurements exceeding $\mathrm{PaCO}_{2}$ measurements by $4-6 \mathrm{mmHg}$ during heavy exercise. Hence during heavy exercise the Bohr estimate of dead space utilising measurements of end-tidal $\mathrm{CO}_{2}$ yields an inappropriately high value because the end-tidal $\mathrm{CO}_{2}$ consistently exceeds the mean alveolar (and arterial) $\mathrm{PCO}_{2}$. A recent method to identify an accurate mean alveolar $\mathrm{CO}_{2}$ from an expiratory capnogram has been validated in experimental animals, and could be incorporated in commercial ventilator systems to calculate a Bohr dead space [4]. However for critically ill patients, that calculation substantially underestimates the more familiar Enghoff modification of the Bohr dead space, which substitutes the $\mathrm{PaCO}_{2}$ measurement for the mean $\mathrm{PACO}_{2}$ measurement [4]. (See the physiological dead space section for mechanisms accounting for increased arterial-alveolar $\mathrm{PCO}_{2}$ differences in abnormal lungs.)

\section{Fowler dead space}

The final fraction of each inspired breath travels no further than the conducting airways, and that anatomical dead space volume includes the upper airways, the larynx and the volume of the tracheo-bronchial tree extending to the acini. In the late 1940's, with the development of a rapidly responding nitrogen meter, Ward Fowler assembled apparatus to measure that anatomical dead space utilising measurements of exhaled nitrogen concentrations immediately following the inspiration of a breath of $100 \%$ oxygen [5]. Fowler's apparatus plotted the volume of the exhaled breath following a single inspiration of $100 \%$ oxygen against the exhaled nitrogen concentration, yielding the curve illustrated in figure 1. The initial fraction of the exhaled breath, termed phase I, contains no nitrogen. The following segment of the exhaled volume, termed phase II, is characterised by progressively increasing concentrations

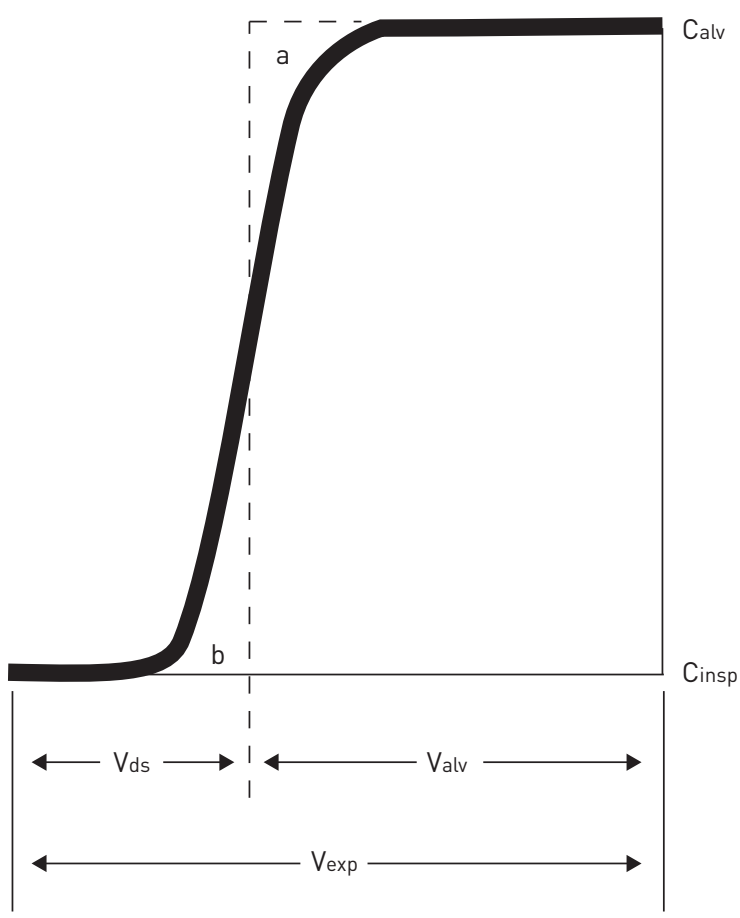

FIGURE 1 Fowler's illustration of the measurement of anatomical dead space, plotting exhaled concentration of nitrogen (C) following an inspired breath of $100 \%$ oxygen against exhaled volume (Vexp), where Cinsp represents the inspired nitrogen concentration $(0 \%)$ and Calv represents the alveolar concentration of nitrogen. The vertical dashed line is positioned so that $\mathrm{a}$ and $\mathrm{b}$ subsume equal areas, and the intersection of the dashed line with the exhaled volume axis defines Vds, the anatomical dead space volume. Valv: alveolar volume. The original notation used by Fowler has been retained. Reproduced from [5] with permission from the publisher. 
of nitrogen prior to reaching the plateau that represents the nitrogen concentration in alveolar gas, termed phase III. The rising slope of phase II reflects the length differences among the large airway pathways within the lung, with shorter length conducting airways contributing alveolar gas concentrations in phase II, and longer regions still contributing 100\% oxygen from dead space gas. Fowler's graphical method to account for the dead space contribution from phase II was to place a straight line along phase III and adjust a vertical line within phase II so that the two areas labelled A and B in figure 1 represent equal areas. The exhaled volume identified by the intersection of that vertical line with the volume axis on the abscissa identifies the dead space, a measurement he termed the physiological dead space, but is now described as the anatomical dead space or Fowler dead space [6].

The Fowler dead space measurement is dependent on the subject size. An approximation suggested by Fowler based on measurements in 45 subjects was that anatomical dead space in cubic centimetres roughly equalled a subject's ideal body weight in pounds [5]. While that anatomical dead space is usually considered a fixed quantity, conducting airway diameter is dependent on lung volume, and when Fowler compared measurements made at different end-inspiratory lung volumes he noted an average $100 \mathrm{~cm}^{3}$ difference in dead space measurements between the largest and smallest starting volumes. In addition, Fowler demonstrated that the measured dead space would decrease if a 20-s breath-hold preceded the exhalation. He postulated this effect primarily arose because of gas diffusion from alveolar regions back into the conducting airways during the breath hold. While a subsequent study did not show significant differences among Fowler measurements carried out with both nitrogen and helium [7], an influence of gas diffusivity was later documented as part of a study utilising inspirations of helium (atomic weight 4) and $\mathrm{SF}_{6}$ (molecular weight 146), demonstrating a smaller Fowler dead space with helium compared with $\mathrm{SF}_{6}[8]$. Gas mixing between small airways and alveolar spaces also takes place as a result of cardiogenic movement, and this effect could also explain the progressive decrease in Fowler dead space measurements observed after a sustained breath hold. The importance of cardiogenic motion in Fowler dead space measurements was documented in an animal study utilising dead space measurements made before and after cardiac arrest, with a $20 \%$ larger dead space measurement obtained after cardiac arrest [9]. A subsequent study established those cardiogenic oscillations as more important than molecular diffusion in reducing the dead space measured by the Fowler method [10]. Hence cardiogenic lung motion and a more modest contribution from gas diffusion combine to decrease the measured Fowler dead space compared with the actual volume of the respiratory pathway between the lips and the respiratory bronchioles.

\section{Physiological dead space}

In 1938, in recognition of the problem with obtaining an appropriate estimate of mean $P_{A C O}$ for calculations using the Bohr equation, Enghoff proposed the substitution of $\mathrm{PaCO}_{2}$ for the mean $P_{\mathrm{ACO}_{2}}$ estimate in the Bohr calculation [11]:

$$
V \mathrm{D} / V \mathrm{~T}=\left(\mathrm{PaCO}_{2}-P \mathrm{ECO}_{2}\right) / \mathrm{PaCO}_{2}
$$

Where $\mathrm{PECO}_{2}$ is the $\mathrm{PCO}_{2}$ in the total mixed exhaled breath. It is the Enghoff modification of the Bohr dead space calculation that is in general use today, and is described as the physiological dead space, where that term represents the sum of the anatomical dead space and the alveolar dead space, where in current usage the alveolar dead space component is defined by the difference between the physiological dead space and the anatomical dead space [12]. The substitution of $\mathrm{PaCO}_{2}$ for the $\mathrm{PACO}_{2}$ avoided the difficulty of identifying an appropriate mean $\mathrm{PACO}_{2}$. However this modification of the Bohr equation added a new component to the dead space estimate that is particularly relevant when the equation is utilised to describe gas exchange in disease. The mean $P_{A C O}$ is always less than mean $\mathrm{PaCO}_{2}$, although this difference is quite small in normal lungs. However, just as any gas exchange abnormality will increase the alveolar-arterial $\mathrm{O}_{2}$ difference, the same statement holds for the arterial-alveolar $\mathrm{CO}_{2}$ difference. Hence the physiological dead space, incorporating the $\mathrm{PaCO}_{2}$, will always be greater than the classic Bohr dead space, and the physiological factors determining the arterial-alveolar $\mathrm{CO}_{2}$ difference can be anything that influences the efficiency of gas exchange. Specifically, in contrast to the original Bohr dead space calculation, the physiological dead space calculation will be sensitive to intrapulmonary shunt and diffusion impairment, and will have a greater sensitivity to alveolar ventilation/perfusion ratio $\left(V^{\prime} \mathrm{A} / Q^{\prime}\right)$ heterogeneity. As the Enghoff modification of the Bohr dead space measurement is sensitive to a range of physiological gas exchange abnormalities, it provides a convenient index of overall gas exchange impairment, but it is important to understand that elevated measurements can arise from multiple mechanisms, dependent on the specific pathophysiology producing the gas exchange impairment. 


\section{Shunt contribution to physiological dead space}

Shunt increases not only the alveolar-arterial $\mathrm{O}_{2}$ difference but also the arterial-alveolar $\mathrm{CO}_{2}$ difference and, therefore, increases calculated physiological dead space. Table 1 presents a simple two-compartment alveolar model without anatomical dead space, containing a shunt compartment and a normal alveolar unit. The alveolar space of the shunt compartment is gas that is in equilibrium with the mixed venous gases and does not contribute to the exhaled gas mixture. One third of the total perfusion of $4.5 \mathrm{~L}$ is delivered to the shunt unit and all of the ventilation is delivered to the normal lung unit, yielding a $V^{\prime} \mathrm{A} / Q^{\prime}$ of 0 for the shunt unit, a $V^{\prime} \mathrm{A} / Q^{\prime}$ of 1.5 for the normal unit, and an overall $V^{\prime} \mathrm{A} / Q^{\prime}$ for the two units combined of 1.0. Assuming a mixed venous $P_{C_{2}}$ of $46 \mathrm{mmHg}$, and sufficient alveolar ventilation to reduce the mixed arterial $\mathrm{CO}_{2}$ to $40 \mathrm{mmHg}$, the lower alveolar $\mathrm{CO}_{2}$ in the single ventilated compartment produces a $7.5 \%$ contribution to that calculated alveolar dead space ( $V \mathrm{D} / V \mathrm{~T}$-alv), even though the model does not contain an unperfused alveolar unit. While a large shunt is required to achieve this result, note that this shunt-mediated contribution to the alveolar dead space calculation would be increased by either a decrease in cardiac output or increase in metabolic rate, where either change would increase the mixed venous $P \mathrm{CO}_{2}$.

\section{$V^{\prime} \mathrm{A} / \mathrm{Q}^{\prime}$ heterogeneity contribution to physiological dead space}

While regional ventilation/perfusion heterogeneity does contribute to the classic Bohr dead space, the physiological dead space is more heavily influenced by $V^{\prime} \mathrm{A} / \mathrm{Q}^{\prime}$ heterogeneity. Table 2 provides a simple three-compartment alveolar model of $V^{\prime} \mathrm{A} / Q^{\prime}$ heterogeneity, again without anatomical dead space, with $V^{\prime} \mathrm{A} / Q^{\prime}$ values of $0.1,1.0$ and 10 in the three compartments to illustrate the effect. As with the example in table 1, the mixed venous $\mathrm{CO}_{2}$ is assumed to be $46 \mathrm{mmHg}$, and the overall alveolar ventilation is adjusted so that the mixed $\mathrm{PaCO}_{2}$ will be $40 \mathrm{mmHg}$. For the three compartments, the overall summed ventilation is $4.2 \mathrm{~L}$ and overall summed perfusion is $4.2 \mathrm{~L}$, with an overall $V^{\prime} \mathrm{A} / Q^{\prime}$ of 1.0 . Combining the $\mathrm{CO}_{2}$ partial pressures in the ventilated and perfused components of the three units yields a calculated physiological dead space of $26 \%$ in this simple $V^{\prime} \mathrm{A} / Q^{\prime}$ heterogeneity model that includes no unperfused alveolar spaces and no anatomical dead space. While the influence of $V^{\prime} \mathrm{A} / \mathrm{Q}^{\prime}$ heterogeneity on the alveolar-arterial $\mathrm{O}_{2}$ difference is well known, its influence on $\mathrm{CO}_{2}$ exchange receives little clinical attention, as most patients can simply increase minute ventilation $\left(V^{\prime} \mathrm{E}\right)$ as $\mathrm{CO}_{2}$ exchange becomes less efficient, thereby concealing the impaired exchange of $\mathrm{CO}_{2}$. Unless a patient requires ventilator support, the requirement for relatively increased $V^{\prime} \mathrm{E}$ is never noticed. John West employed a more sophisticated computer model of $V^{\prime} \mathrm{A} / Q^{\prime}$ heterogeneity to illustrate how disease-relevant degrees of $V^{\prime} \mathrm{A} / Q^{\prime}$ heterogeneity would increase physiological dead space, requiring compensatory increases in $V^{\prime}$ E to maintain normal $\mathrm{PaCO}_{2}$ values [13].

\section{Physiological dead space in an abnormal lung}

In contrast to the simple compartmental models of tables 1 and 2, abnormal lungs ordinarily have combinations of factors that contribute to the physiological dead space measurement. Figure 2 illustrates a distribution of $V^{\prime} \mathrm{A} / Q^{\prime}$ units typical for an abnormal lung that includes increased ventilation/perfusion heterogeneity, shunt and anatomical dead space. Note that a normal lung would have the same bell-shaped distribution of $V^{\prime} \mathrm{A} / Q^{\prime}$ units centred on the overall mean $V^{\prime} \mathrm{A} / Q^{\prime}$ of 1.0 , but the lung units would be contained within a $V^{\prime} \mathrm{A} / \mathrm{Q}^{\prime}$ range between 0.5 and 2.0 . To quantitatively characterise the relative roles of combinations of physiological abnormalities on the physiological dead space measurement requires some familiarity with features of the multiple inert gas elimination technique (MIGET).

To employ MIGET, partial pressures of six intravenously infused inert gases are measured in arterial and mixed venous blood and mixed expired gas to provide the data required for the mathematical model that

\begin{tabular}{|c|c|c|c|}
\hline & $\begin{array}{c}\text { Compartment } 1 \\
\text { (shunt) }\end{array}$ & $\begin{array}{c}\text { Compartment } 2 \\
\text { (ventilated) }\end{array}$ & Combined output \\
\hline$V_{A}^{\prime}$ & $0.0 \mathrm{~L} \cdot \mathrm{min}^{-1}$ & $4.5 \mathrm{~L} \cdot \mathrm{min}^{-1}$ & $4.5 \mathrm{~L} \cdot \mathrm{min}^{-1}$ \\
\hline$Q^{\prime}$ & $1.5 \mathrm{~L} \cdot \mathrm{min}^{-1}$ & $3.0 \mathrm{~L} \cdot \mathrm{min}^{-1}$ & $4.5 \mathrm{~L} \cdot \mathrm{min}^{-1}$ \\
\hline$V^{\prime}{ }_{A} / Q^{\prime}$ & $0.0 \mathrm{~L} \cdot \mathrm{L}^{-1}$ & $1.5 \mathrm{~L} \cdot \mathrm{L}^{-1}$ & $1.0 \mathrm{~L} \cdot \mathrm{L}^{-1}$ \\
\hline $\mathrm{PaCO}_{2}$ & $46 \mathrm{mmHg}$ & $37 \mathrm{mmHg}$ & $40 \mathrm{mmHg}$ \\
\hline $\mathrm{PACO}_{2}$ & $46 \mathrm{mmHg}$ & $37 \mathrm{mmHg}$ & $37 \mathrm{mmHg}$ \\
\hline Alveolar $V_{\mathrm{D}} / V_{\mathrm{T}}$ & & & $7.5 \%$ \\
\hline
\end{tabular}

$V^{\prime}$ A: alveolar ventilation; $Q^{\prime}$ : perfusion; $P_{\mathrm{aCO}}$ : arterial $\mathrm{CO}_{2}$ tension; $P_{\mathrm{ACO}}$ : alveolar $\mathrm{CO}_{2}$ tension; $V_{\mathrm{D}} / \mathrm{VT}$ : alveolar dead space. 
TABLE 2 A simple three-compartment alveolar model of $V^{\prime} A / Q^{\prime}$ heterogeneity

\begin{tabular}{|c|c|c|c|c|}
\hline & $\begin{array}{c}\text { Compartment } 1 \\
\left.\text { (low } V^{\prime} A / Q^{\prime}\right)\end{array}$ & $\begin{array}{l}\text { Compartment } 2 \\
\text { (normal } V^{\prime} A / Q^{\prime} \text { ) }\end{array}$ & $\begin{array}{l}\text { Compartment } 3 \\
\left.\text { (high } V^{\prime} A / Q^{\prime}\right)\end{array}$ & Combined output \\
\hline$V^{\prime}{ }_{A}$ & $0.2 \mathrm{~L} \cdot \mathrm{min}^{-1}$ & $2.0 \mathrm{~L} \cdot \mathrm{min}^{-1}$ & $2.0 \mathrm{~L} \cdot \mathrm{min}^{-1}$ & $4.2 \mathrm{~L} \cdot \mathrm{min}^{-1}$ \\
\hline$V^{\prime} A / Q^{\prime}$ & $0.1 \mathrm{~L} \cdot \mathrm{L}^{-1}$ & $1 \mathrm{~L} \cdot \mathrm{L}^{-1}$ & $10 \mathrm{~L} \cdot \mathrm{L}^{-1}$ & $1 \mathrm{~L} \cdot \mathrm{L}^{-1}$ \\
\hline $\mathrm{PaCO}_{2}$ & $42 \mathrm{mmHg}$ & $40 \mathrm{mmHg}$ & $20 \mathrm{mmHg}$ & $40 \mathrm{mmHg}$ \\
\hline $\begin{array}{l}P_{A C O} \\
\text { Alveolar } V_{D} / V_{T}\end{array}$ & $42 \mathrm{mmHg}$ & $40 \mathrm{mmHg}$ & $20 \mathrm{mmHg}$ & $\begin{array}{c}29.6 \mathrm{mmHg} \\
26 \%\end{array}$ \\
\hline
\end{tabular}

$V^{\prime}$ A: alveolar ventilation; $Q^{\prime}$ : perfusion; $P_{\mathrm{aCO}}$ : arterial $\mathrm{CO}_{2}$ tension; $P_{\mathrm{ACO}}$ : alveolar $\mathrm{CO}_{2}$ tension; $V_{\mathrm{D}} / \mathrm{VT}$ : alveolar dead space.

describes the distribution of ventilation and perfusion in the lung $[14,15]$. The infusion technique with its associated model provides a quantitative estimate of the allocation of pulmonary blood flow to shunt, to regions with $V^{\prime} \mathrm{A} / \mathrm{Q}^{\prime}$ ratios ranging between .001 and 100 , and ventilation to inert gas dead space, a parameter that correlates well with anatomical dead space [16]. While this technique provides a unique means of fully characterising gas exchange abnormalities in humans, useful insights into the physiological dead space calculation in disease can be obtained from examining the basic inert gas data itself $[17,18]$.

In a publication that provided the insights crucial to the subsequent development of MIGET, FARHI [17] demonstrated that the alveolar or arterial partial pressure of an intravenously infused inert gas could be predicted based on the solubility of the gas in blood and the $V^{\prime} \mathrm{A} / \mathrm{Q}^{\prime}$ ratio of the lung unit. For any given $V^{\prime} \mathrm{A} / Q^{\prime}$ value, the predicted arterial (or alveolar) partial pressures of infused inert gases covering a wide range of solubility in blood form a sigmoid curve when plotted against the log of gas solubilities. The single solid line in figure 3 illustrates this retention-solubility diagram for a homogenous lung. If lung units including a distribution of different $V^{\prime} \mathrm{A} / Q^{\prime}$ ratios are combined, the arterial and alveolar lines on the diagram diverge (dashed lines in fig. 3 ). The vertical line on figure 3 labelled $\lambda G$ represents the solubility appropriate for $\mathrm{CO}_{2}$, ranging between 2 and $4 \mathrm{~mL}$ of gas per $\mathrm{mL}$ of blood, depending on the influence of the Haldane effect [20]. The intersection of the $\lambda \mathrm{G}$ line with the arterial and alveolar curves identifies the two partial pressures needed to make an alveolar dead space calculation for the gas with the solubility $\lambda \mathrm{G}$ :

$$
V \mathrm{D} / V \mathrm{~T}=(\text { arterial }- \text { alveolar }) / \text { arterial }
$$

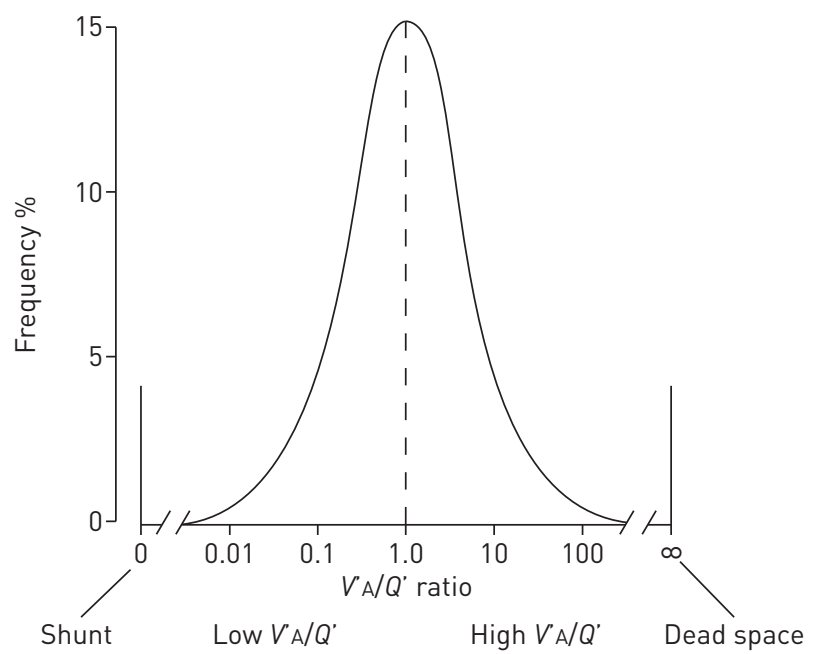

FIGURE 2 Allocation of ventilation and blood flow in an abnormal lung that includes shunt, increased alveolar ventilation/perfusion ratio $\left(V^{\prime} \mathrm{A} / Q^{\prime}\right)$ heterogeneity and increased anatomical dead space. The lung has an overall $V^{\prime} \mathrm{A} / Q^{\prime}$ of 1.0 and has the component lung units sorted according to their individual $V^{\prime} \mathrm{A} / \mathrm{Q}^{\prime}$ ratios. The broad base of the bell-shaped curve reflects substantial overall $V^{\prime} \mathrm{A} / \mathrm{Q}^{\prime}$ heterogeneity. The bar on the left represents the frequency of lung units compromising shunt, and the bar on the right represents lung units receiving ventilation but no pulmonary artery blood flow. Figure reproduced courtesy of R.W. Glenny (Division of Pulmonary and Critical Care Medicine, University of Washington, Seattle, WA, USA). 


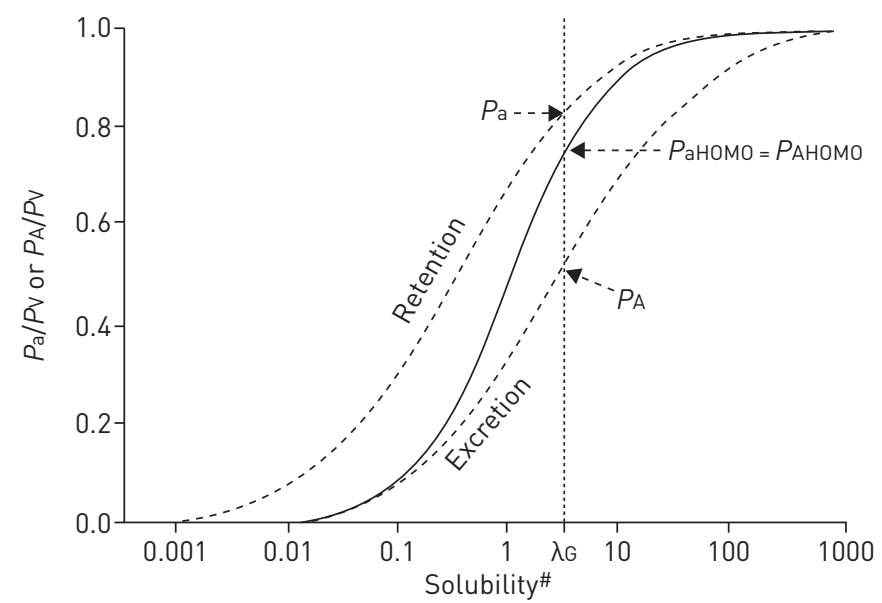

FIGURE 3 Arterial $\left(P_{\mathrm{a}}\right)$ (retention) and alveolar $\left(P_{\mathrm{A}}\right)$ (excretion) partial pressures for intravenously infused inert gases spanning a very large range of solubility in blood. The single solid curved line represents the arterial and alveolar curves of a perfectly homogenous lung $\left(P_{\mathrm{aHOMO}}=P_{\mathrm{AHOMO}}\right)$, and the two dashed lines represent the influence of ventilation/ perfusion heterogeneity that creates an arterial-alveolar partial pressure difference for both respiratory and inert gases. $P_{\mathrm{v}}$ : mixed venous partial pressure; $\lambda \mathrm{G}$ : represents the solubility appropriate for $\mathrm{CO}_{2} .{ }^{\#}$ : solubility is expressed as $\mathrm{mL}$ of gas per $\mathrm{mL}$ of blood at $1 \mathrm{Atm}$. Reproduced from [19] with permission from the publisher.

Applying this graphical inert gas analysis to lung models representing different combinations of abnormal lung physiology, Hlastala and Robertson [19] examined the influence of different degrees of $V^{\prime} \mathrm{A} / Q^{\prime}$ heterogeneity, shunt and anatomical dead space to illustrate the influence of these abnormalities on a physiological dead space calculation, examined over a wide range of inert (and respiratory) gas solubility [19]. Figure 4 illustrates the physiological dead space calculation made over the range of different gas solubilities in three different abnormal lungs, all containing 20\% shunt and $20 \%$ anatomical dead space, in combination with no $V^{\prime} \mathrm{A} / Q^{\prime}$ heterogeneity (fig. 4a), normal $V^{\prime} \mathrm{A} / Q^{\prime}$ heterogeneity (fig. $4 \mathrm{~b}$ ) and increased $V^{\prime} \mathrm{A} / \mathrm{Q}^{\prime}$ heterogeneity (fig. 4c). Note that the physiological dead space in the $\mathrm{CO}_{2}$ solubility range, $\sim 3 \mathrm{~mL}$ of gas per $\mathrm{mL}$ of blood, is most sensitive to the extent of $V^{\prime} \mathrm{A} / \mathrm{Q}^{\prime}$ heterogeneity, with a secondary sensitivity to shunt. In the recent context of investigating the mechanisms responsible for dead space abnormalities in ARDS, WAGNER [21] compared the influence of different degrees of shunt and $V^{\prime} \mathrm{A} / Q^{\prime}$ heterogeneity on physiological dead space, and emphasised the relatively greater influence of $V^{\prime} \mathrm{A} / Q^{\prime}$ heterogeneity on the measurement. A final insight gained from the application of inert gas retention-solubility curves to the understanding of physiological dead space in disease is that any increase the overall $V^{\prime} \mathrm{A} / Q^{\prime}$ ratio (a change that would shift the bell-shaped distribution in fig. 2 to the right on the $V^{\prime} \mathrm{A} / Q^{\prime}$ axis) will also shift all of the curves on the retention-solubility diagram to the right $[17,18]$. Hence a five-fold increase in overall
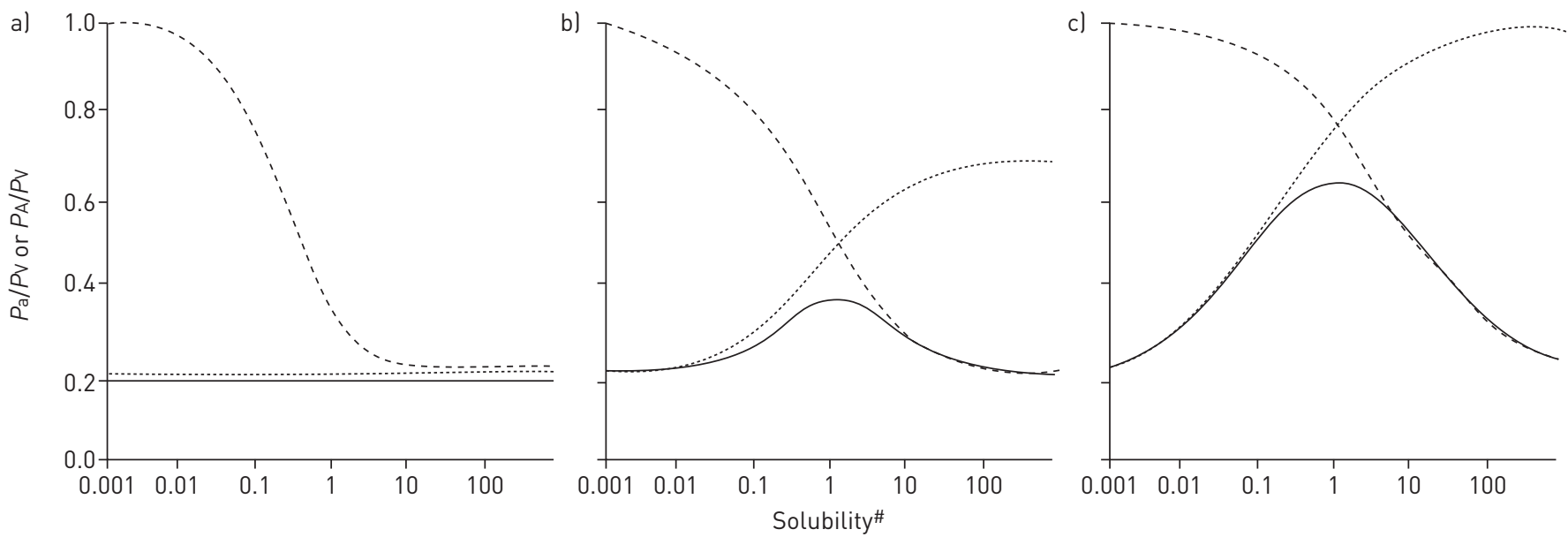

FIGURE 4 Plots based on inert gas retention and excretion values for three model lungs that have $20 \%$ shunt and $20 \%$ anatomical dead space, illustrating the influence of a) no alveolar ventilation/perfusion ratio $\left(V^{\prime} \mathrm{A} / Q^{\prime}\right)$ heterogeneity, b) normal $V^{\prime} \mathrm{A} / Q^{\prime}$ heterogeneity, and c) a high extent of $V^{\prime} \mathrm{A} / Q^{\prime}$ heterogeneity. The dashed lines identify the physiological dead space calculation for the entire range of inert gas solubility. The solid lines represent the inert gas arterial-alveolar differences and the dotted lines represent the venous admixture calculation for the inert gases. ${ }^{\#}$ : solubility is expressed as $\mathrm{mL}$ of gas per $\mathrm{mL}$ of blood at $1 \mathrm{Atm}$. Reproduced from [19] with permission from the publisher. 
$V^{\prime} \mathrm{A} / \mathrm{Q}^{\prime}$ ratio will shift all of the figure 4 curves five units to the right along the solubility axis. As gas solubility in blood is fixed, any increase in the mean $V^{\prime} \mathrm{A} / Q^{\prime}$ value by increased ventilation and/or decreased perfusion will also increase the calculated physiological dead space. Of note, the influence of a substantial increase in the mean $V^{\prime} \mathrm{A} / Q^{\prime}$ ratio on the physiological dead space measurement was first described by John West, based on calculations utilising his initial computer model of ventilation/perfusion interactions in the lung [22].

\section{Physiological dead space during exercise}

The initial studies of gas exchange during a progressive work exercise test by WASSERMAN et al. [23] demonstrated a progressive decrease in physiological dead space from rest to maximal exercise, with a normal response identified as a $V \mathrm{D} / V \mathrm{~T}$ of $<20 \%$ at maximal effort. This decrease is readily explained by the progressive increase in tidal volume during the first half of a progressive work exercise test to $\sim 60 \%$ of the vital capacity, associated with an anatomical dead space that increases only trivially with the increase in end-inspiratory volume induced by exercise. The decrease in dead space during exercise was originally postulated to also include improved ventilation/perfusion matching, but measurements of ventilation/ perfusion heterogeneity during exercise in normal humans assessed by MIGET have not demonstrated a decrease in overall ventilation/perfusion heterogeneity at low and moderate levels of exercise [24], the period in a progressive work exercise test when the $V \mathrm{D} / V \mathrm{~T}$ decreases most appreciably [23]. At the highest tolerated levels of exercise, $V^{\prime} \mathrm{A} / Q^{\prime}$ heterogeneity increases modestly [24], and is associated with the well-known increase in the alveolar-arterial $\mathrm{O}_{2}$ difference. From these MIGET observations, it might be expected that physiological $V \mathrm{D} / V \mathrm{~T}$ should increase slightly with maximal effort, but increases at maximal effort are inconsistent and small in comparison with the overall decrease in $V \mathrm{D} / V \mathrm{~T}$ seen early during a progressive exercise work test.

\section{Can "true" alveolar dead space also exchange $\mathrm{CO}_{2}$ ?}

The original interpretation of alveolar dead space was as a compartment in alveolar spaces that received no pulmonary artery perfusion, although the current definition of the term alveolar dead space refers to anything in the physiological dead space that does not include anatomical dead space [12]. While ventilated alveolar regions without pulmonary artery perfusion (here defined as "true" alveolar dead space) develop following acute pulmonary emboli and should lead to abnormal dead space measurements, physiological dead space as a diagnostic test for pulmonary emboli was found to lack sensitivity for all but the most massive occlusions. Some of that lack of sensitivity may be secondary to gas exchange provided by the bronchial circulation. Alveolar regions of lung with acute loss of pulmonary artery perfusion can receive capillary perfusion in variable amounts from connections to the bronchial circulation and drain into the mixed pulmonary venous output to the left atrium [25]. With sustained occlusion, this bronchial artery perfusion of alveolar capillaries can be appreciably augmented [25]. Although the systemic bronchial artery blood perfusing those alveolar capillaries will not be further oxygenated during that second pass through the lung, it will exchange additional $\mathrm{CO}_{2}$. Hence for segments of embolised lung that only receive blood from the bronchial arteries, those units function as high $V^{\prime} \mathrm{A} / Q^{\prime}$ units from the perspective of $\mathrm{CO}_{2}$ gas exchange, and physiological dead space measurements will underrepresent the true extent of pulmonary artery occlusion. In the setting of severe bronchiectasis, the elimination of $\mathrm{CO}_{2}$ via the bronchial circulation can provide a clinically significant contribution to overall $\mathrm{CO}_{2}$ exchange, a situation occasionally recognised following the embolisation of bronchial arteries for acute haemoptysis in patients with severe bronchiectasis [26].

\section{Interaction between anatomical dead space and $V^{\prime} A / Q^{\prime}$ heterogeneity}

The presence of both anatomical dead space and instrument dead space means that the first portion of each breath is re-inspired alveolar gas. In the presence of substantial $V^{\prime} \mathrm{A} / \mathrm{Q}^{\prime}$ heterogeneity, the re-inspired alveolar gas might be mixed and, therefore, the re-inspired dead space could alter the measured heterogeneity among the different units of an abnormal lung. The effect of gas re-inspired from a well-mixed "common" dead space in a lung with overall $V^{\prime} \mathrm{A} / Q^{\prime}$ heterogeneity was first analysed utilising the perspective of the $\mathrm{O}_{2}-\mathrm{CO}_{2}$ diagram by Ross and FARHI [27]. Based on the assumption that the re-inspired dead space gas was well mixed, they demonstrated that this influence would reduce the measured extent of overall $V^{\prime} \mathrm{A} / Q^{\prime}$ heterogeneity and hence reduce the measured alveolar dead space contribution to the physiological dead space. A second possibility is that the exhaled dead space gas remains "personal", that is, each $V^{\prime} \mathrm{A} / Q^{\prime}$ unit would re-inspire its own exhaled gas, an effect that would have no influence on measured $V^{\prime} \mathrm{A} / Q^{\prime}$ heterogeneity. The "common" and "personal" hypotheses for the distribution of re-inspired gas were modelled by ForTune and WAGNER [28] in normal lungs. They demonstrated that for normal lungs, the assumption that re-inspired dead space gas was "personal" was an adequate description. However when successive increments of external instrument dead space were added in an animal study, progressively increasing the proportion of re-inspired gas, PETRINI et al. [29] 
demonstrated that there was an appreciable reduction in the extent of externally measured $V^{\prime} \mathrm{A} / \mathrm{Q}^{\prime}$ heterogeneity. Hence with the addition of larger amounts of instrument dead space, the calculated alveolar dead space component of the physiological dead space will decrease without changing the actual $V^{\prime} \mathrm{A} / \mathrm{Q}^{\prime}$ distribution within the lung.

\section{Diffusion impairment and physiological dead space}

Carbon dioxide, as a relatively soluble gas in tissue, is not ordinarily considered subject to diffusion impairment during pulmonary gas exchange. However, the delivery of $\mathrm{CO}_{2}$ to the alveolar spaces from pulmonary capillary blood requires the catalysis of carbonic anhydrase within the erythrocyte, as the principal transport of metabolically produced $\mathrm{CO}_{2}$ to the lung is in the form of bicarbonate rather than dissolved $\mathrm{CO}_{2}$ [13]. Since that chemical reaction requires time, a very fast capillary transit time could possibly lead to a transpulmonary partial pressure profile identical to that seen with a molecular diffusion impairment. Model studies have suggested that $\mathrm{PCO}_{2}$ in alveolar gas might be slightly lower that the systemically sampled $\mathrm{PaCO}_{2}$ if there was decreased alveolar capillary residence time for this reaction [30]. In addition, any drug that impairs the action of erythrocyte carbonic anhydrase can increase the $P_{\mathrm{aCO}_{2}}$ to $\mathrm{PACO}_{2}$ difference, a reversible drug effect previously documented in burn patients treated with the old topical sulfonamides with substantial carbonic anhydrase inhibitory effects [31]. Acetazolamide, a weak diuretic currently used to prevent symptoms in high altitude sojourners, acts by inhibition of renal carbonic anhydrase, and also influences erythrocyte carbonic anhydrase. While inhibition could produce a mild arterial-alveolar $\mathrm{CO}_{2}$ gradient in the lung, at recommended clinical doses a measurable influence would probably only be apparent during heavy exercise [30].

\section{Dead space measurements in ARDS}

Clinical interest in the physiological dead space measurement was reawakened by the publication by NUCKTON et al. [32] in 2002, linking dead space measurements to prognosis in the ARDS. Physiological dead space was measured in 179 mechanically ventilated ARDS patients on the day of the syndrome onset. The mean dead space fraction was 0.54 in eventual survivors and 0.63 in patients who succumbed to the syndrome, and the risk of death increased with every 0.05 increment in dead space. The physiological dead space measurement outperformed all of the previous prognostic measures including traditional measures of oxygenation impairment, lung compliance and illness severity. The authors postulated that the abnormal measurement was due to regions with blocked microcirculation that remained ventilated, in short, that the abnormality was secondary to the creation of "true" alveolar dead space. Cероvка et al. [33] performed a subsequent study of ARDS patients ventilated with $6 \mathrm{~cm}^{3} \cdot \mathrm{kg}^{-1}$ tidal volumes, demonstrating a nearly identical predictive power of physiological dead space measurements, but no significant correlation between pulmonary artery pressures and the dead space measurements. Further confirmation of the prognostic value of physiological dead space measurement in both acute lung injury (ALI) and ARDS was presented by SiDDIKI et al. [34] utilising previously collected ARDS network data from 1896 patients. While arterial blood gas and ventilator measurements were available, the mixed expired $\mathrm{CO}_{2}$ values were not measured, and hence mixed expired $\mathrm{CO}_{2}$ had to be calculated based on predicted $\mathrm{CO}_{2}$ production rates appropriate for acutely ill mechanically ventilated patients. Based on the arterial $\mathrm{CO}_{2}$ measurements and predicted mixed expired $\mathrm{CO}_{2}$ concentrations, SIDDIKI et al. [34] found that at both day 1 and day 3 of ARDS diagnosis, patients with a dead space fraction in excess of 0.50 had a risk for death that increased with every additional 0.10 increment in dead space fraction, a risk prediction that almost exactly equalled the predictive power of the complete $\mathrm{CO}_{2}$ measurements on ARDS patients described by NuCKTON et al. [32] and CEPOVKA et al. [33].

\section{Factors contributing to the elevated $V_{D} / V_{T}$ in ARDS}

By contrast to the postulated development of unperfused regions of lung in ARDS to explain the elevated physiological dead space, both increased $V^{\prime} \mathrm{A} / \mathrm{Q}^{\prime}$ heterogeneity and shunt are the more likely contributors to that observation $[21,35]$. However, because the gas exchange characteristics of ARDS are multifactorial, it is instructive to review previous studies of ALI performed using MIGET, which provides quantitative measurement of the influence of shunt, $V^{\prime} \mathrm{A} / Q^{\prime}$ heterogeneity and dead space. Coffey et al. [36] utilised an oleic acid model of ALI to study the influence of positive end-expiratory pressure (PEEP) on dead space calculations, including MIGET measurements to fully characterise the gas exchange responses. After the injury stabilised in the anaesthetised animals, gas exchange measurements were acquired at randomly allocated levels of PEEP ranging between 0 and $20 \mathrm{cmH}_{2} \mathrm{O}$. Physiological dead space measurements were made at each level of PEEP, and the contributions of the components of shunt, $V^{\prime} \mathrm{A} / Q^{\prime}$ heterogeneity, anatomical dead space, and alveolar dead space (defined as $V^{\prime} \mathrm{A} / Q^{\prime}>100$ ) were noted. In this animal model, progressive addition of PEEP improved both shunt and $V^{\prime} \mathrm{A} / Q^{\prime}$ heterogeneity, with an initial reduction in the physiological dead space. However, higher levels of PEEP increased the Fowler dead space, accounting for increased ventilation to regions with $V^{\prime} \mathrm{A} / Q^{\prime}>100$, and modestly increased the physiological dead space. In this animal model with randomly allocated PEEP levels, the high $V^{\prime} \mathrm{A} / Q^{\prime}$ 
regions resolved when PEEP levels were lowered, so the development of very high $V^{\prime} \mathrm{A} / Q^{\prime}$ regions with high PEEP was the result of PEEP-created increases in Fowler dead space and zone 3 regions of lung rather than ventilated lung regions with microvascular blockade that had been postulated in the human ARDS study of NUCKTON et al. [32].

Three studies utilising MIGET to investigate gas exchange in ARDS patients, all performed in the era when application of high tidal volumes $\left(10-15 \mathrm{~cm}^{3} \cdot \mathrm{kg}^{-1}\right)$ was the clinical standard, described various combinations of shunt, very low $V^{\prime} \mathrm{A} / Q^{\prime}$ regions and increased overall $V^{\prime} \mathrm{A} / \mathrm{Q}^{\prime}$ heterogeneity, but with an infrequent incidence of isolated high $V^{\prime} \mathrm{A} / Q^{\prime}$ regions among all patients studied [37-39]. The study of RALPH et al. [38] included data obtained during progressive application of PEEP and did not observe the development of high $V^{\prime} \mathrm{A} / \mathrm{Q}^{\prime}$ units at the higher levels of PEEP that had been noted in the dog model of ALI. A current era MIGET study of ARDS patients by FeIHL et al. [40] comparing the gas exchange responses to ventilation with tidal volumes of $10 \mathrm{~cm}^{3} \cdot \mathrm{kg}^{-1}$ or $6 \mathrm{~cm}^{3} \cdot \mathrm{kg}^{-1}$ showed minimal evidence of high $V^{\prime} \mathrm{A} / Q^{\prime}$ regions at $10 \mathrm{~cm}^{3} \cdot \mathrm{kg}^{-1}$ tidal volumes. With the $6 \mathrm{~cm}^{3} \cdot \mathrm{kg}^{-1}$ tidal volumes, the shunt fraction increased, but evidence for high $V^{\prime} \mathrm{A} / \mathrm{Q}^{\prime}$ regions had essentially vanished, as evidenced by the very small retention-excretion differences for the most soluble gases. The patient population in the FEIHL et al. [40] study had an average physiological $V \mathrm{D} / V \mathrm{~T}$ of $65 \%$ at both $10 \mathrm{~cm}^{3} \cdot \mathrm{kg}^{-1}$ and $6 \mathrm{~cm}^{3} \cdot \mathrm{kg}^{-1}$ tidal volumes, and while the lower tidal volume did have a proportionately larger anatomical dead space, the unchanged $V \mathrm{D} / V \mathrm{~T}$ observed at $6 \mathrm{~cm}^{3} \cdot \mathrm{kg}^{-1}$ was explained by the higher cardiac output and lower mixed venous $P \mathrm{CO}_{2}$ at that lower tidal volume. This ARDS patient population, with no demonstrable high $V^{\prime} \mathrm{A} / Q^{\prime}$ component to their gas exchange when receiving $6 \mathrm{~cm}^{3} \cdot \mathrm{kg}^{-1}$ tidal volumes, had a higher overall $V \mathrm{D} / V \mathrm{~T}$ than the mean values from patients in the NuCKTON et al. [32] and CEPOvкA et al. [33] studies. Hence, MIGET studies of patients with ARDS have not revealed any consistent elevation in unperfused alveolar dead space, and indeed the MIGET study performed utilising the current $6 \mathrm{~cm}^{3} \cdot \mathrm{kg}^{-1}$ tidal volumes demonstrated a striking absence of any high $V^{\prime} \mathrm{A} / Q^{\prime}$ component, despite severe elevations in the physiological $V \mathrm{D} / V \mathrm{~T}$ measurement.

A final potential influence on the physiological $V \mathrm{D} / V \mathrm{~T}$ in the most severely ill ARDS patients relates to the overall $V^{\prime} \mathrm{A} / Q^{\prime}$ ratio. For patients with a very low cardiac output who are receiving very high $V^{\prime} \mathrm{E}$, the overall $V^{\prime} \mathrm{A} / \mathrm{Q}^{\prime}$ ratio may exceed $5 \mathrm{~L} \cdot \mathrm{L}^{-1}$. An increase in the mean $V^{\prime} \mathrm{A} / \mathrm{Q}^{\prime}$ ratio will shift all the curves on the retention-solubility diagram to the right, increasing the physiological dead space measurement, just as a decrease in the mean $V^{\prime} \mathrm{A} / Q^{\prime}$ ratio would have the opposite effect. Hence while physiological dead space abnormalities in ARDS patients are a compelling indicator of prognosis, the interpretation that abnormal values primarily represent the creation of lung parenchyma that is ventilated but not perfused is not consistent with the human data obtained utilising MIGET. The physiological dead space abnormalities in ARDS patients supported with the currently utilised $6 \mathrm{~cm}^{3} \cdot \mathrm{kg}^{-1}$ tidal volumes arise primarily as a consequence of the presence of both shunt and increased low and mid-range $V^{\prime} \mathrm{A} / Q^{\prime}$ heterogeneity [40].

\section{Abnormal exercise dead space measurements in heart failure}

Exercise studies done on patients with stable severe heart failure have demonstrated an abnormally elevated exercise ventilation response that is present at all levels of exertion. The ventilatory equivalent for $\mathrm{CO}_{2}\left(V^{\prime} \mathrm{E} /\right.$ carbon dioxide production $\left.\left(V^{\prime} \mathrm{CO}_{2}\right)\right)$, calculated as the slope of the two measurements acquired throughout a maximal progressive exercise test, has become a standard tool for evaluation of patients with severe heart failure [41]. The finding of a $V^{\prime} \mathrm{E} / V^{\prime} \mathrm{CO}_{2}>34 \mathrm{~L} \cdot \mathrm{L}^{-1}$ is associated with adverse cardiac outcomes, and the risk increases progressively for patients with additional increases in that measurement [42]. The elevated $V^{\prime} \mathrm{E} / V^{\prime} \mathrm{CO}_{2}$ in a heart failure patient is primarily attributable to alveolar hyperventilation, as peripheral chemoreceptor hyperactivity, demonstrated by an enhanced ventilation response to hypoxia, is a consistent feature in heart failure patients with significant impairment [43]. However, that augmented exercise ventilation response in the most impaired patients is also associated with an elevated physiological dead space during exercise [44-46]. The hypothesis that this elevated exercise dead space reflected regions of very high $V^{\prime} \mathrm{A} / Q^{\prime}$ in the lung [45] was not consistent with the single MIGET study of heart failure patients at rest that revealed no increases in high $V^{\prime} \mathrm{A} / Q^{\prime}$ regions or increases in inert gas dead space [47]. While there are currently no MIGET studies of severe heart failure patients during exercise, an alternative explanation for the increased dead space arises as a consequence of the exercise hyperventilation and impaired cardiac output. The consistent feature of the exercise response in severe heart failure patients is the exceptionally high ventilation relative to cardiac output during a progressive work exercise test. The most impaired patients can barely double their cardiac output from rest to maximal effort [48]. That disproportionate increase in exercise ventilation associated with an impaired cardiac output can yield overall $V^{\prime} \mathrm{A} / \mathrm{Q}^{\prime}$ ratios that may approach $10 \mathrm{~L} \cdot \mathrm{L}^{-1}$ during exercise in the most impaired patients. That increase in overall $V^{\prime} \mathrm{A} / Q^{\prime}$ ratio will shift the retention and excretion curves in figure 3 to the right, and therefore also shift all the derived curves in figure 4 to the right. As the solubility of $\mathrm{CO}_{2}$ remains unchanged, the exercise associated $V^{\prime} \mathrm{A} / Q^{\prime}$ shift leads to an increased physiological dead space measurement for $\mathrm{CO}_{2}$. Hence a consistent explanation for the elevated dead space measurements seen 
during exercise in the most impaired heart failure patients is the abnormally elevated overall $V^{\prime} \mathrm{A} / Q^{\prime}$ ratio and its interaction with $V^{\prime} \mathrm{A} / \mathrm{Q}^{\prime}$ heterogeneity $[49,50]$.

\section{Abnormal exercise dead space measurements in pulmonary hypertension}

While normal subjects ordinarily demonstrate at least a 50\% reduction in physiological dead space during heavy exercise compared with their resting measurement, patients with pulmonary hypertension typically fail to show any reduction in dead space during exercise, despite demonstrating typical increases in tidal volume as the exercise intensity increases. The original explanation proposed for this observation was that exercise produced more high $V^{\prime} \mathrm{A} / Q^{\prime}$ regions in the lungs of those patients. A MIGET study of resting patients with idiopathic pulmonary hypertension (IPH) or chronic thromboembolic pulmonary hypertension (CTEPH) by DANTZKER et al. [51] revealed a modest increase in both $V^{\prime} \mathrm{A} / Q^{\prime}$ heterogeneity and shunt, although resting physiological dead space still remained within normal limits. A follow-up study by DANTZKER et al. [52], which included MIGET measurements taken during exercise on seven pulmonary hypertension patients, found that the extent of overall $V^{\prime} \mathrm{A} / \mathrm{Q}^{\prime}$ heterogeneity during exercise remained unchanged. The exercise study patients had a mean resting physiological $V \mathrm{D} / V \mathrm{~T}$ of $42 \%$ that increased to $44 \%$ with maximal effort. The patients showed the characteristic haemodynamic and ventilatory responses to exercise seen in patients with severe pulmonary hypertension, with marked exercise hyperventilation and only modest increases in cardiac output leading to exercise mean $V^{\prime} \mathrm{A} / Q^{\prime}$ ratios in the range of 3-12. As the extent of $V^{\prime} A / Q^{\prime}$ heterogeneity and shunt fraction remained unchanged in the transition from rest to exercise, this study represents the best documented instance of the influence of an exercise-elevated mean $V^{\prime} \mathrm{A} / Q^{\prime}$ ratio on the physiological dead space measurement. While the increase in mean $V^{\prime} \mathrm{A} / Q^{\prime}$ with exercise appears to be an important determinant of the abnormal physiological dead space measurement in pulmonary hypertension patients, their underlying $V^{\prime} \mathrm{A} / Q^{\prime}$ heterogeneity and shunt are still important contributors to the exercise measurement abnormality, as normal subjects at maximal exercise will show at least two-fold increases in mean $V^{\prime} \mathrm{A} / Q^{\prime}$, and still manifest the normal decrease in $V \mathrm{D} / V \mathrm{~T}$ with progressive exercise.

A recent study by ZHAi et al. [53] comparing exercise physiological dead space measurements in patients with IPH and CTEPH found higher $V \mathrm{D} / V \mathrm{~T}$ in the CTEPH patients, despite comparable resting haemodynamic measurements in the two groups. In addition, unlike the IPH patients, the functional status of the CTEPH patients did not correlate with the extent of physiological dead space abnormality, and the authors suggested that the balance of factors determining the physiological dead space in CTEPH during exercise might be different from that in IPH. DANTZKER et al. [51] did not identify an increased inert gas dead space in the three CTEPH patients included in their study, but as the bronchial artery flow increases dramatically to chronically embolised regions of lung [25], those chronically embolised regions will function as high $V^{\prime} \mathrm{A} / Q^{\prime}$ units, thereby increasing the $V^{\prime} \mathrm{A} / Q^{\prime}$ heterogeneity contribution to the physiological dead space calculation. Another explanation for the higher exercise $V \mathrm{D} / V \mathrm{~T}$ observed in the CTEPH patients could be a relatively higher mean exercise $V^{\prime} \mathrm{A} / \mathrm{Q}^{\prime}$ in comparison with the IPH patients [53].

\section{Summary and conclusion}

The physiological dead space is defined as including anatomical dead space and alveolar dead space components. In normal subjects, the measurement is primarily determined by the contribution of the anatomical dead space, with a small addition from the alveolar dead space attributable to normal ventilation/perfusion heterogeneity. However, in a wide range of pulmonary disease conditions the alveolar dead space component becomes more important, and the original concept that it reflects the influence of regions of lung parenchyma receiving no pulmonary artery perfusion is never an adequate explanation. Any of the physiological mechanisms contributing to an increased arterial-alveolar $\mathrm{CO}_{2}$ difference will increase the measured physiological dead space, but ordinarily the extent of overall $V^{\prime} \mathrm{A} / Q^{\prime}$ heterogeneity is the most important contributor. In addition, in the presence of increased $V^{\prime} \mathrm{A} / Q^{\prime}$ heterogeneity, any stimulus increasing the overall mean $V^{\prime} \mathrm{A} / Q^{\prime}$, such as extreme hyperventilation with exercise, will further increase the physiological dead space measurement.

\section{References}

Bohr C. [Ueber die Lungenathmung]. Skand Arch Physiol 1891; 2: 236-268.

2 Krogh A, Lindhard J. The volume of the dead space in breathing and the mixing of gases in the lungs of man. J Physiol 1917; 51: 59-90.

3 Jones NL, Robertson DG, Kane JW. Difference between end-tidal and arterial PCO2 in exercise. J Appl Physiol Respir Environ Exerc Physiol 1979; 47: 954-960.

4 Suarez-Sipmann F, Santos A, Böhm SH, et al. Corrections of Enghoffs dead space formula for shunt effects still overestimate Bohr's dead space. Respir Physiol Neurobiol 2013; 189: 99-105.

5 Fowler WS. Lung function studies; the respiratory dead space. Am J Physiol 1948; 154: 405-416.

6 Klocke RA. Dead space: simplicity to complexity. J Appl Physiol 2006; 100: 1-2. 
7 Bartels J, Severinghaus JW, Forster RE, et al. The respiratory dead space measured by single breath analysis of oxygen, carbon dioxide, nitrogen or helium. J Clin Invest 1954; 33: 41-48.

8 Crawford $\mathrm{AB}$, Makowska $\mathrm{M}$, Paiva $\mathrm{M}$, et al. Convection- and diffusion-dependent ventilation maldistribution in normal subjects. J Appl Physiol 1985; 59: 838-846.

9 Engel LA, Menkes H, Wood LD, et al. Gas mixing during breath holding studied by intrapulmonary gas sampling. J Appl Physiol 1973; 35: 9-17.

10 Fukuchi Y, Roussos CS, Macklem PT, et al. Convection, diffusion and cardiogenic mixing of inspired gas in the lung; an experimental approach. Respir Physiol 1976; 26: 77-90.

11 Enghoff H. [Volumen inefficax. Bermekungen zur Frage des shadlichen Raumes. Upsala Laekarefoeren]. Foerh 1938; 44: 191-218.

12 West JB. Respiratory Physiology - The Essentials. 6th Edn. Philadelphia, Lippincott, Williams \& Wilkins, 2000

13 West JB. Causes of carbon dioxide retention in lung disease. N Engl J Med 1971; 284: 1232-1236.

14 Wagner PD, Naumann PF, Laravuso RB. Simultaneous measurement of eight foreign gases in blood by gas chromatography. J Appl Physiol 1974; 36: 600-605.

15 Wagner PD, Saltzman HA, West JB. Measurement of continuous distributions of ventilation-perfusion ratios: theory. J Appl Physiol 1974; 36: 588-599.

16 Dueck R, Wagner PD, West JB. Effects of positive end-expiratory pressure on gas exchange in dogs with normal and edematous lungs. Anesthesiology 1977; 47: 359-366.

17 Farhi LE. Elimination of inert gas by the lung. Respir Physiol 1967; 3: 1-11.

18 West JB, Wagner PD, Derks CM. Gas exchange in distributions of VA-Q ratios: partial pressure-solubility diagram. J Appl Physiol 1974; 37: 533-540.

19 Hlastala MP, Robertson HT. Inert gas elimination characteristics of the normal and abnormal lung. J Appl Physiol Respir Environ Exerc Physiol 1978; 44: 258-266.

20 Robertson HT, Hlastala MP. Elevated alveolar $\mathrm{PCO}_{2}$ relative to predicted values during normal gas exchange. J Appl Physiol Respir Environ Exerc Physiol 1977; 43: 357-364.

21 Wagner PD. Causes of a high physiological dead space in critically ill patients. Crit Care 2008; 12: 148.

22 West JB. Ventilation-perfusion inequality and overall gas exchange in computer models of the lung. Respir Physiol 1969; 7: 88-110.

23 Wasserman K, Van Kessel AL, Burton GG. Interaction of physiological mechanisms during exercise. J Appl Physiol 1967; 22: 71-85.

24 Wagner PD, Gale GE, Moon RE, et al. Pulmonary gas exchange in humans exercising at sea level and simulated altitude. J Appl Physiol 1986; 61: 260-270.

25 Deffebach ME, Charan NB, Lakshminarayan S, et al. The bronchial circulation. Small, but a vital attribute of the lung. Am Rev Respir Dis 1987; 135: 463-481.

26 Henig NR, Glenny RW, Aitken ML. A hypertrophied bronchial circulatory system may participate in gas exchange. Lancet 1998; 351: 113.

27 Ross BB, Farhi LE. Dead-space ventilation as a determinant in the ventilation-perfusion concept. J Appl Physiol 1960; 15: 363-371.

28 Fortune JB, Wagner PD. Effects of common dead space on inert gas exchange in mathematical models of the lung. J Appl Physiol 1979; 47: 896-906.

29 Petrini MF, Robertson HT, Hlastala MP. Interaction of series and parallel dead space in the lung. Respir Physiol 1983; 54: 121-136.

30 Swenson ER, Maren TH. A quantitative analysis of $\mathrm{CO}_{2}$ transport at rest and during maximal exercise. Respir Physiol 1978; 35: 129-159.

31 White MG, Asch MJ. Acid-base effects of topical mafenide acetate in the burned patient. N Engl J Med 1971; 284: 1281-1286.

32 Nuckton TJ, Alonso JA, Kallet RH, et al. Pulmonary dead-space fraction as a risk factor for death in the acute respiratory distress syndrome. N Engl J Med 2002; 346: 1281-1286.

33 Cepkova M, Kapur V, Ren X, et al. Pulmonary dead space fraction and pulmonary artery systolic pressure as early predictors of clinical outcome in acute lung injury. Chest 2007; 132: 836-842.

34 Siddiki $\mathrm{H}$, Kojicic M, Li G, et al. Bedside quantification of dead-space fraction using routine clinical data in patients with acute lung injury: secondary analysis of two prospective trials. Crit Care 2010; 14: R141.

35 Robertson HT, Swenson ER. What do dead-space measurements tell us about the lung with acute respiratory distress syndrome?. Respir Care 2004; 49: 1006-1007.

36 Coffey RL, Albert RK, Robertson HT. Mechanisms of physiological dead space response to PEEP after acute oleic acid lung injury. J Appl Physiol Respir Environ Exerc Physiol 1983; 55: 1550-1557.

37 Dantzker DR, Brook CJ, Dehart P, et al. Ventilation-perfusion distributions in the adult respiratory distress syndrome. Am Rev Respir Dis 1979; 120: 1039-1052.

38 Ralph DD, Robertson HT, Weaver LJ, et al. Distribution of ventilation and perfusion during positive end-expiratory pressure in the adult respiratory distress syndrome. Am Rev Respir Dis 1985; 131: 54-60.

39 Mélot $\mathrm{C}$, Lejeune $\mathrm{P}$, Leeman $\mathrm{M}$, et al. Prostaglandin E1 in the adult respiratory distress syndrome. Benefit for pulmonary hypertension and cost for pulmonary gas exchange. Am Rev Respir Dis 1989; 139: 106-110.

40 Feihl F, Eckert P, Brimioulle S, et al. Permissive hypercapnia impairs pulmonary gas exchange in the acute respiratory distress syndrome. Am I Respir Crit Care Med 2000; 162: 209-215.

41 Coats AJ. Why ventilatory inefficiency matters in chronic heart failure. Eur Heart J 2005; 26: 426-427.

42 Ponikowski P, Francis DP, Piepoli MF, et al. Enhanced ventilatory response to exercise in patients with chronic heart failure and preserved exercise tolerance: marker of abnormal cardiorespiratory reflex control and predictor of poor prognosis. Circulation 2001; 103: 967-972.

43 Ponikowski P, Chua TP, Anker SD, et al. Peripheral chemoreceptor hypersensitivity: an ominous sign in patients with chronic heart failure. Circulation 2001; 104: 544-549.

44 Myers J, Salleh A, Buchanan N, et al. Ventilatory mechanisms of exercise intolerance in chronic heart failure. Am Heart J 1992; 124: 710-719.

45 Wasserman K, Zhang YY, Gitt A, et al. Lung function and exercise gas exchange in chronic heart failure. Circulation 1997; 96: 2221-2227. 
46 Johnson RL Jr. Gas exchange efficiency in congestive heart failure II. Circulation 2001; 103: 916-918.

47 Adnot S, Radermacher P, Andrivet P, et al. Effects of sodium-nitroprusside and urapidil on gas exchange and ventilation-perfusion relationships in patients with congestive heart failure. Eur Respir J 1991; 4: 69-75.

48 Agostoni PG, Wasserman K, Perego GB, et al. Non-invasive measurement of stroke volume during exercise in heart failure patients. Clin Sci 2000; 98: 545-551.

49 Robertson HT. Gas exchange consequences of left heart failure. Compr Physiol 2011; 1: 621-634.

50 Robertson HT. Excess ventilation during exercise and prognosis in chronic heart failure. Am J Respir Crit Care Med 2012; 185: 227.

51 Dantzker DR, Bower JS. Mechanisms of gas exchange abnormality in patients with chronic obliterative pulmonary vascular disease. J Clin Invest 1979; 64: 1050-1055.

52 Dantzker DR, D’Alonzo GE, Bower JS, et al. Pulmonary gas exchange during exercise in patients with chronic obliterative pulmonary hypertension. Am Rev Respir Dis 1984; 130: 412-416.

53 Zhai $\mathrm{Z}$, Murphy $\mathrm{K}$, Tighe $\mathrm{H}$, et al. Differences in ventilatory inefficiency between pulmonary arterial hypertension and chronic thromboembolic pulmonary hypertension. Chest 2011; 140: 1284-1291. 